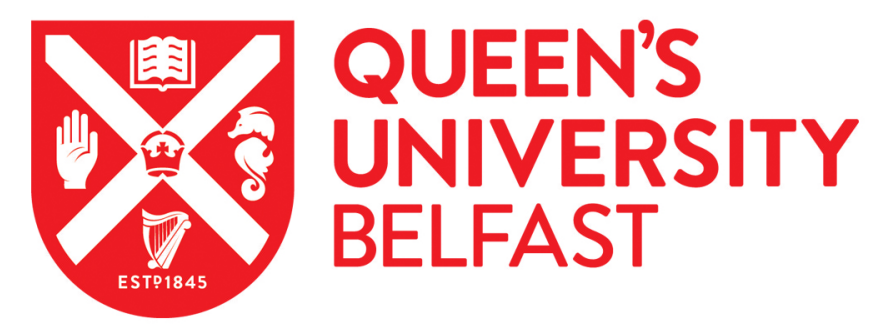

\title{
A self-healing, adaptive and conductive polymer composite ink for 3D printing of gas sensors
}

Wu, T., Gray, E., \& Chen, B. (2018). A self-healing, adaptive and conductive polymer composite ink for 3D printing of gas sensors. Journal of Materials Chemistry C, 6, 6200-6207. https://doi.org/10.1039/c8tc01092g

Published in:

Journal of Materials Chemistry C

Document Version:

Peer reviewed version

Queen's University Belfast - Research Portal:

Link to publication record in Queen's University Belfast Research Portal

Publisher rights

Copyright 2018 Royal Society of Chemistry. This work is made available online in accordance with the publisher's policies. Please refer to any applicable terms of use of the publisher.

\section{General rights}

Copyright for the publications made accessible via the Queen's University Belfast Research Portal is retained by the author(s) and / or other copyright owners and it is a condition of accessing these publications that users recognise and abide by the legal requirements associated with these rights.

Take down policy

The Research Portal is Queen's institutional repository that provides access to Queen's research output. Every effort has been made to ensure that content in the Research Portal does not infringe any person's rights, or applicable UK laws. If you discover content in the Research Portal that you believe breaches copyright or violates any law, please contact openaccess@qub.ac.uk. 


\section{Journal of \\ Materials Chemistry C}

\section{Accepted Manuscript}

This article can be cited before page numbers have been issued, to do this please use: T. Wu, E. Gray and

B. Chen, J. Mater. Chem. C, 2018, DOI: 10.1039/C8TC01092G.

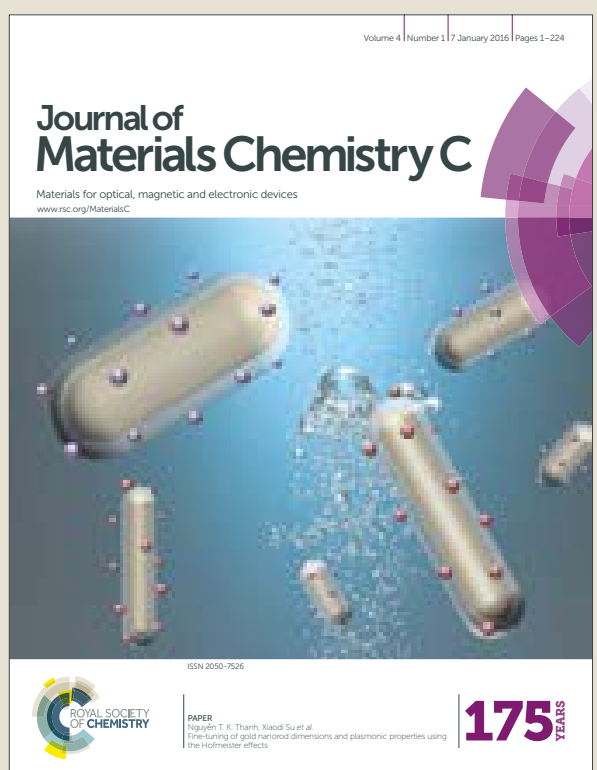

This is an Accepted Manuscript, which has been through the Royal Society of Chemistry peer review process and has been accepted for publication.

Accepted Manuscripts are published online shortly after acceptance, before technical editing, formatting and proof reading. Using this free service, authors can make their results available to the community, in citable form, before we publish the edited article. We will replace this Accepted Manuscript with the edited and formatted Advance Article as soon as it is available.

You can find more information about Accepted Manuscripts in the author guidelines.

Please note that technical editing may introduce minor changes to the text and/or graphics, which may alter content. The journal's standard Terms \& Conditions and the ethical guidelines, outlined in our author and reviewer resource centre, still apply. In no event shall the Royal Society of Chemistry be held responsible for any errors or omissions in this Accepted Manuscript or any consequences arising from the use of any information it contains. 


\title{
Journal of Materials Chemistry C
}

\section{ARTICLE}

\section{Self-healing, adaptive and conductive polymer composite ink for 3D printing of gas sensors}

Received 00th January 20xx, Accepted 00th January 20xx

DOI: $10.1039 / x 0 \times x 00000 x$ www.rsc.org/

\author{
Tongfei $\mathrm{Wu}^{\mathrm{a}, \mathrm{b}}$, Euan Gray ${ }^{\mathrm{a}}$, and Biqiong Chen ${ }^{\mathrm{a}, \mathrm{c}^{*}}$
}

\begin{abstract}
Self-healing conductive polymer composite ink was formulated for 3D extrusion printing of flexible electronics. It was composed of polyborosiloxane (PBS) matrix and 5 vol.\% of electrochemically exfoliated graphene. The printability was derived from the chemical-activated mechanically adaptive property (MAP) of PBS. The MAP of PBS and the composite ink was studied through rheological measurements, and the non-Newtonian nature was analyzed using the Carreau-Yasuda model. With methanol vapor as a representative stimulus, the underpinning mechanism of MAP of PBS, which involved the methanol-induced alcoholysis of the cross-linking boron/oxygen dative bonds in PBS, was further investigated by infrared spectroscopy. The self-healing, adaptive and conductive composite ink could be used to print 3D structures and devices on a common polydimethylsiloxane flexible substrate. A 3D-printed gas sensor with responses to various chemical vapors was demonstrated as a potential application of this novel composite ink.
\end{abstract}

\section{Introduction,}

3D-printing technology features the capability to create complex structural or functional objects through adding materials in a layer-by-layer manner with satisfactory geometric accuracy ${ }^{1,2}$. The most popular 3D-printing techniques include direct ink writing $^{3}$, fused deposition modeling $(\mathrm{FDM})^{4}$, selective laser sintering ${ }^{5}$, polyjet ${ }^{6}$, stereo lithography ${ }^{7}$, digital light processing ${ }^{8,9}$, and freeform reversible embedding ${ }^{10}$. The requirements for the printing material vary with the nature of mass delivery process of the 3D-printing technique. Nevertheless, the flowability of the printing material is essential for all the techniques. Therefore, the printing material must be in liquid ${ }^{3}$, powder ${ }^{5}$ or another flowable form ${ }^{11}$. It should also be able to solidify rapidly to preserve the desired structures, which can be achieved either physically and/or chemically ${ }^{12}$. Over the last decade, wellselected new printing materials have continued to emerge, covering all the categories in materials science: polymers, metals, ceramics and composites ${ }^{13}$. An increasing interest has focused on the use of 3D-printing technology for the manufacture of electronics, like 3D-printed circuits, electrodes, transistors, sensors and actuators ${ }^{14-17}$. The concept of printed electronics was initially demonstrated in the $1990 \mathrm{~s}^{18-21}$ and has

\footnotetext{
a. Department of Materials Science and Engineering, University of Sheffield, Mappin Street, Sheffield, S1 3JD, UK.

b. School of Materials Science and Engineering, Sun Yat-sen University, Guangzhou, 510275, China.

c. School of Mechanical and Aerospace Engineering, Queen's University Belfast, Stranmillis Road, Belfast BT9 5AH, UK. E-mail: b.chen@qub.ac.uk.

Electronic Supplementary Information (ESI) available: Data fitting for the response and recovery times of PBS/G5 for sensing various chemical vapors. See
} DOI: $10.1039 / \times 0 \times x 00000 x$ become an attractive alternative to conventional technologies by enabling the seamless creation of large-area, flexible devices at a low cost ${ }^{22}$. In particular, as the booming of flexible electronics, the growing demand for the manufacture of electronics on customized substrates boosts the research on 3D-printed electronics.

Owing to its flexibility, nozzle-based scanning deposition techniques are the most common method for the manufacture of 3D-printed electronics: inkjet printing and extrusion printing of liquid and viscoelastic materials, respectively, offering a new approach for the fabrication of functional devices ${ }^{23-25}$. Recently, viscoelastic, conductive polymer composite inks have been attracting a growing attention in 3D-printed electronics ${ }^{26}$. Various functional devices have been developed based on polymer composite greases/doughs, such as 3D-printed highly stretchable sensors made from carbon conductive grease ${ }^{27}$, conductive cellulose composite grease-based 3D-printed batteries $^{28}$, and 3D-printed body-patchable strain sensors made from a carbon-based composite dough ${ }^{29}$. Conductive thermoplastic composite solids are applicable to FDM extrusion printing to fabricate self-supporting devices, such as carbon black/thermoplastic polymer composites for 3Dprinted sensors and capacitive buttons ${ }^{14}$, reduced graphene oxide/polylactic acid composites for flexible circuits $^{30}$, multiwalled carbon nanotube/thermoplastic polyurethane nanocomposites for highly elastic strain sensors ${ }^{31}$. Lately, Jakus et al. reported a graphene/hyperelastic polyester suspension (consisting of majority graphene and minority polyester) for energy storage and biomedical electronics. ${ }^{32}$ Different from the liquid-solid phase transition-based solidification method in FDM, the post-printing solidification of this composite suspension was governed by the rapid evaporation of solvent (dichloromethane). 
Polyborosiloxane (PBS) is a highly viscoelastic supramolecular material that exhibits an intrinsic self-healing characteristic due to the dynamic association/dissociation of boron/oxygen dative bond ${ }^{33}$. Because of the dynamic nature of boron/oxygen dative bond, PBS behaves like an elastic solid for high Deborah numbers under a rapid strain variation, yet like a viscous fluid over longer testing time scales ${ }^{34}$. Grapheneincorporated PBS composites exhibited excellent electromechanical sensitivity ${ }^{35}$. Moreover, the dynamic nature of boron/oxygen dative bond also leads to temperaturedependent ${ }^{36,37}$ and chemical-activated mechanically adaptive properties (MAPs) ${ }^{38}$. In this work, we present a formulation of a simple conductive polymer composite ink based on PBS with 5 vol.\% electrochemically exfoliated graphene for 3D printing of electronics on polydimethylsiloxane (PDMS). The conductive composite ink is prepared by solution blending of the two components in a solvent followed by solution casting. Owing to the chemical-activated MAP of PBS, the composite ink is flowable in an atmosphere of methanol saturated vapor and recovers solid-like state when returning into the open air. The MAP of PBS and the composite ink are studied through rheological measurements, with shear-thinning behaviour analyzed using the Carreau-Yasuda model. The mechanism of methanol-induced MAP is investigated by infrared spectroscopy. The composite ink possesses mechanically and electrically self-healing capability and chemical-responsive conductivity. These qualities enable the composite to be used for extrusion printing of 3D structures and devices on PDMS substrates. A sensor that is able to detect various chemical vapors is 3D-printed, demonstrating a potential application of this novel composite ink.

\section{Results and discussion}

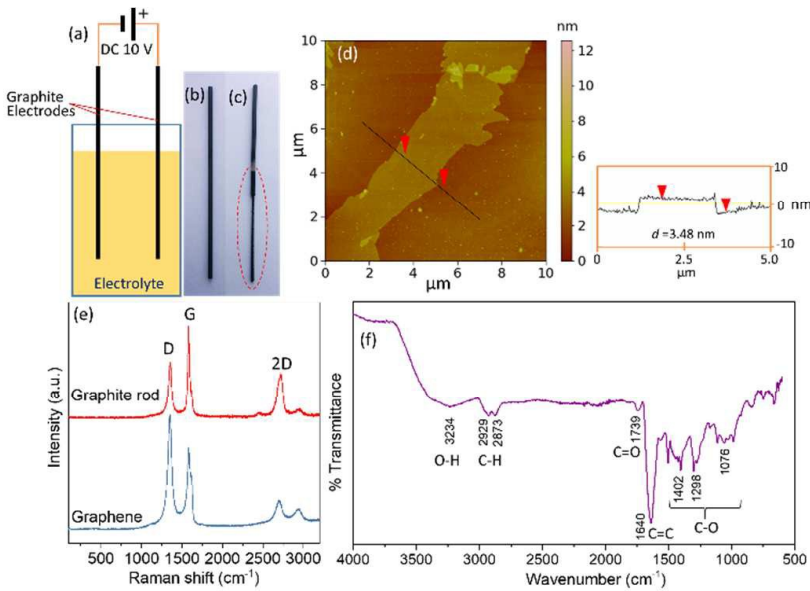

Figure 1. (a) Schematic illustration of the setup for electrochemical exfoliation of graphite. Photographs of graphite rod electrodes after electrochemical exfoliation: (b) cathode and (c) anode. (d) AFM image and height profile of the as-prepared graphene nanosheets. (e) Raman spectra of graphite rod and the as-prepared graphene. (f) FTIR spectrum of the as-prepared graphene.

Preparation of self-healing PBS/graphene composite ink (PBS/G5)
Graphene was prepared by electrochemical exfoliation of graphite using graphite rods as the counter and working electrodes, as illustrated in Figure 1(a-c). The electrochemical exfoliation occurred at the anode (the working electrode). The exfoliated graphene was washed and dispersed in $\mathrm{N}$ methylpyrrolidone (NMP). The as-prepared graphene was deposited on mica through evaporation of NMP and the morphology was investigated by atomic force microscopy (AFM), which is shown in Figure 1d. The thickness of graphene monolayer was $\sim 0.72 \mathrm{~nm}^{39}$. The AFM height profile of the asprepared graphene shows a thickness of $\sim 3.48 \mathrm{~nm}$, confirming the multilayer nature (4-5 layers). Raman spectroscopy was used to identify defects in the as-prepared graphene in comparison with graphite rod, as shown in Figure 1e. The D peak at $1350 \mathrm{~cm}^{-1}$ was caused by the breathing mode of the $\mathrm{sp}^{2}$ carbon atoms and activated by the existence of defects such as edges, functional groups, or structural disorders ${ }^{40}$. The intensity ratio of $D$ and $G$ peaks $\left(I_{D} / I_{G}\right)$ for graphite rod was 0.62. After electrochemical exfoliation, $I_{D} / I_{G}$ reached 1.4 , indicating a higher degree of defects. The functional groups present on the as-prepared graphene was studied by FTIR in Figure 1f: hydroxyl $\mathrm{OH}\left(3234 \mathrm{~cm}^{-1}\right)$, carboxyl $\mathrm{C}=\mathrm{O}$ and $\mathrm{C}-\mathrm{O}$ (1739 and $1402 \mathrm{~cm}^{-1}$, respectively), aromatic $\mathrm{C}=\mathrm{C}\left(1640 \mathrm{~cm}^{-1}\right)$, epoxy $\left(1298 \mathrm{~cm}^{-1}\right)$ and alkoxy $\left(1076 \mathrm{~cm}^{-1}\right)^{41}$. The electrical conductivity of the as-prepared graphene was investigated by surface resistance measurement. A graphene sheet with a thickness of $50 \mu \mathrm{m}$ was prepared by vacuum filtration. The surface resistance of the sheet was measured as $79.6 \mathrm{k} \Omega$ square $^{-1}$, which is relatively large in comparison to the typical surface resistance range of graphene $\left(10^{2} \sim 10^{4} \Omega \text { square }^{-1}\right)^{42}$, probably due to the high degree of defects.
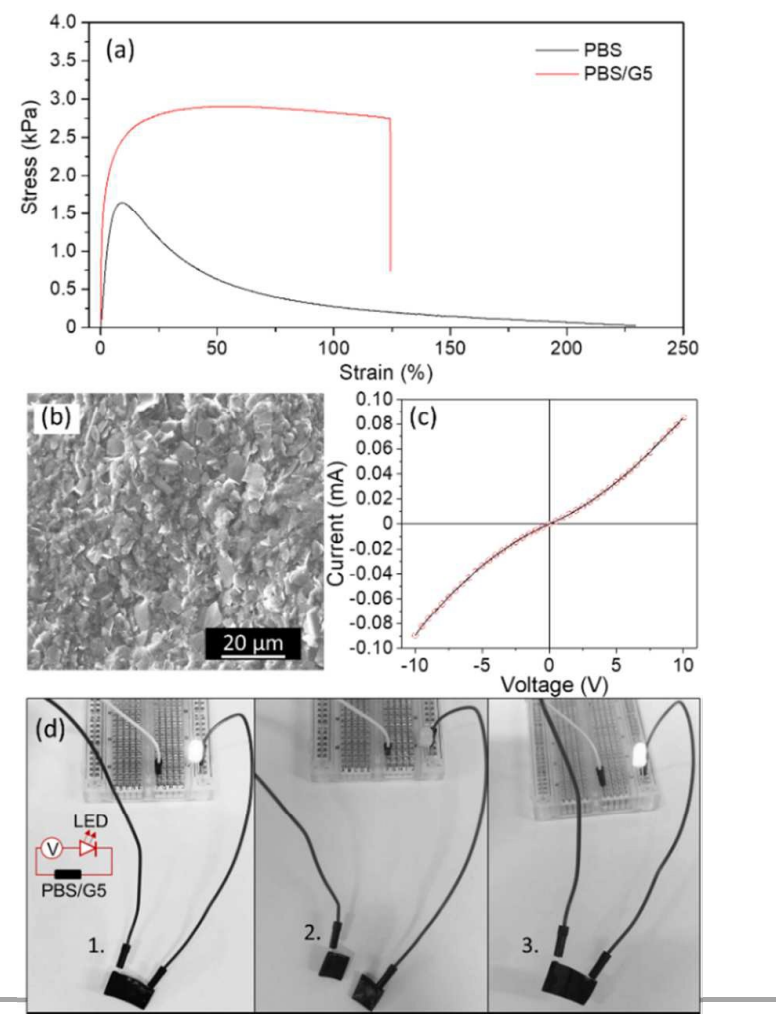
Figure 2. (a) Representative tensile stress-strain curves of PBS and PBS/G5. (b) SEM image of PBS/G5. (c) I-V curve for PBS/G5. (d) Demonstration of the healing process for PBS/G5 in an LED-integrated circuit (Inset): 1. Undamaged (light on), 2. completely severed (light off), and 3 . healing of the sample (light on) by bringing two parts together.

The as-prepared graphene was used as a conducting filler to prepare a conductive PBS/graphene composite, PBS/G5 (containing 5 vol.\% graphene, a content greater than the percolation threshold, 1.75 vol. $\%{ }^{35}$ ), by solution blending followed by casting. The reinforcement of graphene on the mechanical properties of PBS was investigated by tensile testing, with representative stress-strain curves shown in rigure 2a. Ihe tensile strength, Young's modulus and elongation at break were $1.6 \pm 0.5 \mathrm{kPa}, 33 \pm 8 \mathrm{kPa}$ and $227 \pm 34 \%$ for PBS and $2.9 \pm 0 . / \mathrm{kPa}, 1 \mathrm{SO} \pm 23 \mathrm{kPa}$ and $124 \pm 41 \%$ for $\mathrm{PBS} / \mathrm{G}$, demonstrating the efficient stress transfer and reinforcement in the composite, similar to the cases with PBS/carbon nanotube composites ${ }^{38}$. The scanning electron microscopy (SEM) image of PBS/G5 in Figure $2 \mathrm{~b}$ shows a relatively uniform dispersion of graphene sheets in PBS matrix, most of which also contact each other to form a graphene network that provides an efficient reinforcing effect as well as a continuous conducting channel. From the current-voltage (I-V) curve for PBS/G5 between $-10 \mathrm{~V}$ to $10 \mathrm{~V}$ in Figure $2 \mathrm{c}$, it can be seen that its resistance decreased with increasing voltage from 0 to $5 \mathrm{~V}$. The electrical conductivity was calculated as $3.24 \times 10^{-5} \mathrm{~S} \mathrm{~cm}^{-1}$ based on the linear region (5-10 V). A key feature of PBS based composites is the intrinsic, room-temperature mechanically self-healing property ${ }^{33}$. It means, when PBS/G5 suffers cracks or fractures, simply bringing the broken pieces together will lead to spontaneous healing. Figure $2 \mathrm{~d}$ demonstrates the electrically and mechanically self-healing behavior of PBS/G5 in an electrical circuit. The electrical conductivity of PBS/G5 after self-healing was $3.22 \times 10^{-5} \mathrm{~S} \mathrm{~cm}^{-1}$, suggesting the conductive healing efficiency was as high as $99.4 \%$.

\section{Rheological studies of PBS and PBS/G5}

Figure 3a-d demonstrate the methanol-activated mechanically adaptive behavior of PBS. The original PBS was solid-like (Figure 3a) and was completely liquefied after kept in methanol saturated vapor for $24 \mathrm{~h}$ (Figure $3 \mathrm{~b}$ and $3 \mathrm{c}$ ). It was noted that, notwithstanding the significant change in appearance, the measured methanol absorption of PBS was as low as 2.5 wt.\%. After kept in ambient conditions for $12 \mathrm{~h}$, the sample recovered its mechanical strength owing to the evaporation of methanol (Figure 3d). For quantitative analysis, the dynamic mechanical properties of solidified and liquefied samples were compared by rheological testing as shown in Figure $3 e$ and $3 f$. As expected, the storage modulus ( $\left.G^{\prime}\right)$, loss modulus (G"), and the magnitude of complex viscosity $\left(\left|\eta^{*}\right|\right)$ of the liquefied sample were evidently lower than those of the solidified sample. For instance, $G^{\prime}, G^{\prime \prime}$ and $\left|\eta^{*}\right|$ of PBS at angular frequency $(\omega)$ of $1 \mathrm{rad} \mathrm{s}^{-1}$ were 625,92 and 267 times higher than those of liquefied PBS, respectively, while the differences were 135, 217 and 136 times for PBS/G5 and liquefied PBS/G5. Owing to the reinforcement effect of graphene, G', G" and $\left|\eta^{*}\right|$ of PBS/G5 were notably higher than those of PBS.

The standard linear solid (SLS) model (Inset of Figure 3(e)) was applied to describe viscoelastic properties of PBS in previous reports ${ }^{34.35}$, where $G_{1}$ and $G_{2}$ are shear moduli and $\eta$ is the viscosity. The relationship between the rheological measurements in oscillation mode and SLS model are given in the following equations ${ }^{35}$.

$$
\begin{aligned}
& G^{\prime}=G_{2}+\frac{G_{1} \tau^{2} \omega^{2}}{\tau^{2} \omega^{2}+1} \\
& G^{\prime \prime}=\frac{G_{1} \tau \omega^{2}}{\tau^{2} \omega^{2} \mid 1}
\end{aligned}
$$

where $\tau=\eta / G_{1}$ is the relaxation time of the material. $G_{1}, G_{2}$ and $\tau$ were determined as $1.23 \times 10^{5} \mathrm{~Pa}, 1.69 \times 10^{3} \mathrm{~Pa}$ and 0.266 $s$ for PBS, respectively. As shown in Figure $3 e$, SLS model did not fit the data of PBS and PBS/G5 well, especially at low frequencies for PBS and high frequencies for PBS/G5. A similar conclusion was also reached by previous literature ${ }^{35}$. This deviation was attributed to the assumption of the constant $\eta$ in SLS mode, where factually PBS is non-Newtonian.

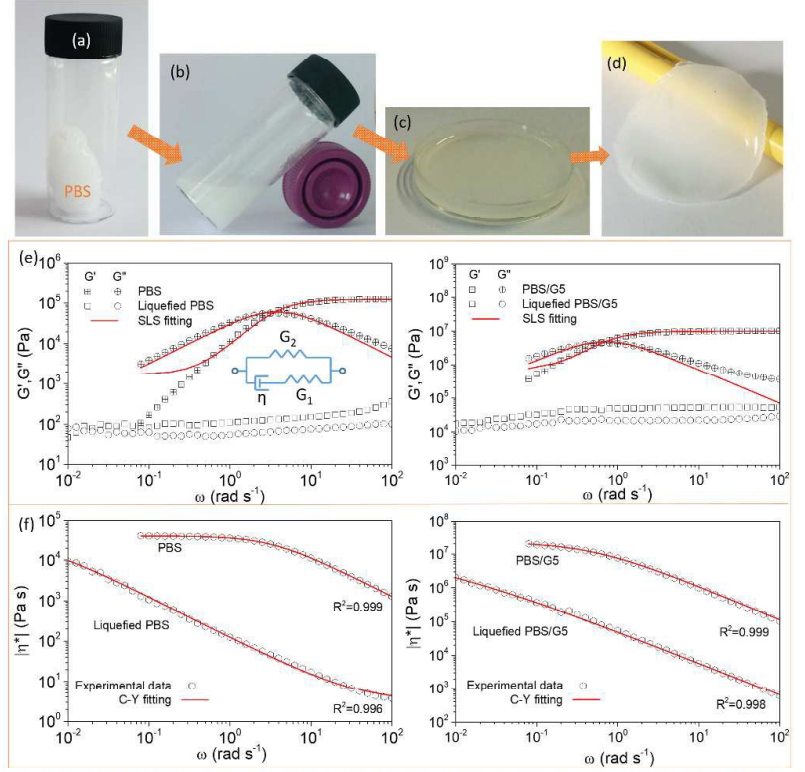

Figure 3. Illustration of methanol-activated mechanically adaptive property of PBS: (a) original, (b) liquefied after being kept in saturated methanol vapor for $24 \mathrm{~h}$, (c) molded into a dish, and (d) re-solidified after being kept under ambient conditions for $12 \mathrm{~h}$. Rheological behavior of PBS and PBS/G5 as a function of angular frequency $(\omega)$ : (e) storage modulus ( $G^{\prime}$ ) and loss modulus (G"), and (f) the magnitude of complex viscosity $(|\eta *|)$. The inset of $(e)$ is spring-dashpot diagram of standard linear solid (SLS) model.

In Figure $3 f,\left|\eta^{*}\right|$ obviously shows frequency-dependent behavior for both samples. $\left|\eta^{*}\right|$ of PBS trends to be a constant at the low frequency end and decreases with increasing frequency, showing a shear-thinning behavior. The CarreauYasuda (C-Y) model, as presented by Equation $(3)^{43,44}$, was widely used to describe the steady-state viscosity $(\eta)$ of nonNewtonian fluid continuously for all the shear rates $\dot{\gamma}>0$, which has been successfully applied for shear-thinning liquid polymers, like silicone oils and bitumen ${ }^{45,46} . \eta_{0}$ and $\eta_{\infty}$ are the zero and infinite shear viscosity, indicating the Newtonian plateau at both high and low shear rate ends, describing a 
similar profile of the frequency dependence of $\left|\eta^{*}\right|$ for PBS in the studied range.

$$
\eta=\eta_{\infty}+\left(\eta_{0}-\eta_{\infty}\right)\left[1+(\lambda \dot{\gamma})^{a}\right]^{(n-1) / a}
$$

where $0 \leq n \leq 1,0 \leq \lambda$ and $a$ are the material shape parameters. $1 / \lambda$ is the critical shear rate at which the viscosity starts to

Table 1. Summary of Carreau-Yasuda model parameters for PBS and PBS/G5.

\begin{tabular}{ccccccc}
\hline Sample & $\left|\eta_{0}^{*}\right|(\mathrm{Pa} \mathrm{s})$ & $\left|\eta_{\infty}^{*}\right|(\mathrm{Pa} \mathrm{s})$ & $\lambda\left(\mathrm{s} \mathrm{rad}^{-1}\right)$ & $a$ & $n$ & $1 / \lambda\left(\mathrm{rad} \mathrm{s}^{-1}\right)$ \\
\hline PBS & $3.96 \times 10^{7}$ & $6.86 \times 10^{3}$ & 0.309 & 1.44 & 0 & 3.24 \\
Liquefied PBS & $2.44 \times 10^{7}$ & $3.09 \times 10^{3}$ & 199 & 1.41 & 0 & $5.03 \times 10^{-3}$ \\
PBS/G5 & $2.32 \times 10^{10}$ & $1.52 \times 10^{6}$ & 0.206 & 0.991 & 0 & 4.85 \\
Liquefied PBS/G5 & $2.34 \times 10^{10}$ & $1.99 \times 10^{4}$ & 491 & 0.432 & 0.03 & $2.03 \times 10^{-3}$ \\
\hline
\end{tabular}

decrease. This model predicts Newtonian fluid behavior $\eta=\eta_{0}$ when $n=1$ and/or $\lambda=0$. The value of $n$ approaching zero indicates increasingly shear-thinning behavior. To apply $\mathrm{C}-\mathrm{Y}$ model to the dynamic measurements, Cox and Merz provide a rule to connect the dynamic viscosity function of $\left|\eta^{*}(\omega)\right|$ and the steady-state viscosity function of $\eta(\dot{\gamma}):\left|\eta^{*}(\omega)\right|=\eta(\dot{\gamma}=\omega)^{47}$. Assuming that the Cox-Merz rule is valid for PBS, the function of $\eta(\dot{\gamma})$ can be reconstructed to be applicable for $\left|\eta^{*}(\omega)\right|$, as shown in Equation $(4)^{48}$.

$$
\left|\eta^{*}\right|=\left|\eta_{\infty}^{*}\right|+\left(\left|\eta_{0}^{*}\right|-\left|\eta_{\infty}^{*}\right|\right)\left[1+(\lambda \omega)^{a}\right]^{(n-1) / a}
$$

Through the regression analysis of the data with $\mathrm{C}-\mathrm{Y}$ model in Figure $3 f$, it can be seen that $\mathrm{C}-\mathrm{Y}$ model is applicable to describe the non-Newtonian behavior of PBS and PBS/G5. The best-fit parameters are summarized in Table 1 . For both PBS samples, the value of $n$ equals to about 0 , suggesting a strongly shear-thinning behavior. $\left|\eta_{0}^{*}\right|$ and $\left|\eta_{\infty}^{*}\right|$ show a more than three orders of magnitude difference in both samples. The critical frequency at which the viscosity starts to decrease reflected by $1 / \lambda$ is $5.03 \times 10^{-3} \mathrm{rad} \mathrm{s}^{-1}$ for liquefied PBS (out of the measurement range of this study). With the dynamic crosslinkage by boron/oxygen dative bond, the critical frequency raised from $5.03 \times 10^{-3} \mathrm{rad} \mathrm{s}^{-1}$ to $3.24 \mathrm{rad} \mathrm{s}^{-1}$ for PBS. It was also noted that the viscosity of silicone oil used was approximately 0.34 Pa s. The viscosity of liquefied PBS was remarkably higher than that of silicone oil, which might be due to the presence of boric acid derivatives and the changes in the chemical structure of silicone oil after reacting with boric acid. $\left|\eta_{0}^{*}\right|$ and $\left|\eta_{\infty}^{*}\right|$ show a 6 orders of magnitude difference for liquefied PBS/G5 and a 4 orders of magnitude difference for PBS/G5. With the addition of graphene, the critical frequency raised from $3.24 \mathrm{rad} \mathrm{s}^{-1}$ to $4.85 \mathrm{rad} \mathrm{s}^{-1}$, which might be caused by the confinement effect of graphene on the motion of PBS.

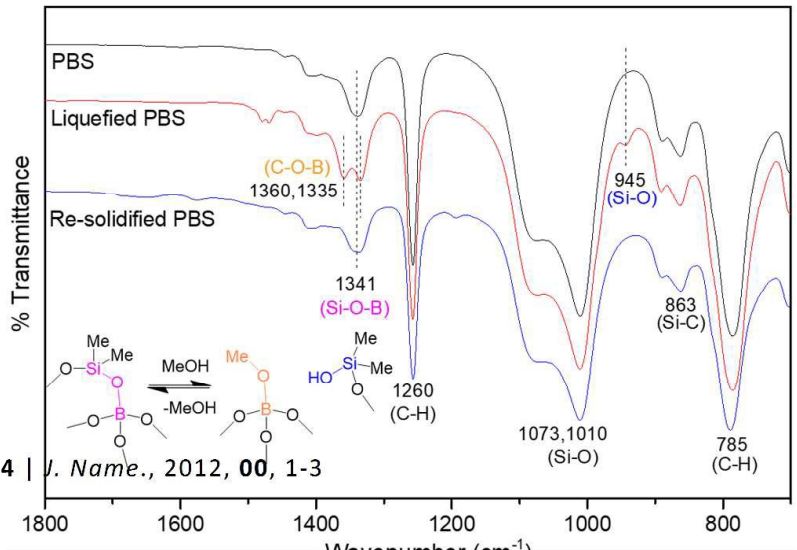

Figure 4. FTIR spectra of PBS samples. The inset is mechanism of methanol-activated mechanically adaptive property of PBS. (delete $s$ after Wavenumber)

To study the chemical changes induced by methanol vapor, Fouriertransform infrared (FTIR) spectra of as-prepared PBS, PBS liquefied by methanol vapor and re-solidified PBS are compared in Figure 4. The peak at $863 \mathrm{~cm}^{-1}$ is assigned to stretching vibration of $\mathrm{Si}-\mathrm{C}$ and the band at $1010 \mathrm{~cm}^{-1}$ with a shoulder at $1073 \mathrm{~cm}^{-1}$ (Si-O stretching) is assigned to $\mathrm{Si}-\mathrm{O}-\mathrm{Si}$ moiety ${ }^{49,50}$. Other peaks at $785 \mathrm{~cm}^{-1}$ (C-H rocking), $1260 \mathrm{~cm}^{-1}$ (C-H symmetric bending), $1409 \mathrm{~cm}^{-1}$ (asymmetric bending), $2905 \mathrm{~cm}^{-1}$ (C-H symmetric stretching) and $2961 \mathrm{~cm}^{-1}$ (C-H asymmetric stretching) correspond to the vibrations of $\mathrm{Si}-\mathrm{CH}_{3}$ moiety ${ }^{51}$. The characteristic absorption of boron/oxygen dative bond in Si-O-B moiety is observed at $1341 \mathrm{~cm}^{-1}$ for PBS. ${ }^{52}$ After being liquefied by methanol, two peaks at 1335 and $1360 \mathrm{~cm}^{-1}$ formed, which correspond to C-O-B moiety ${ }^{53}$, and a band at $945 \mathrm{~cm}^{-1}$ for the Si-O stretching of Si-O-H moiety appeared ${ }^{54-}$ 56. This suggests the methanol-induced alcoholysis of boron/oxygen dative bond in Si-O-B moiety, resulting in the cleavage of the cross-linkages of PBS and leading to the chemical-activated mechanically adaptive property of PBS, as illustrated in the Inset of Figure 4. After re-solidification, the characteristic absorption of Si-O-B moiety at $1341 \mathrm{~cm}^{-1}$ recovered, exhibiting no difference to that of as-prepared PBS.

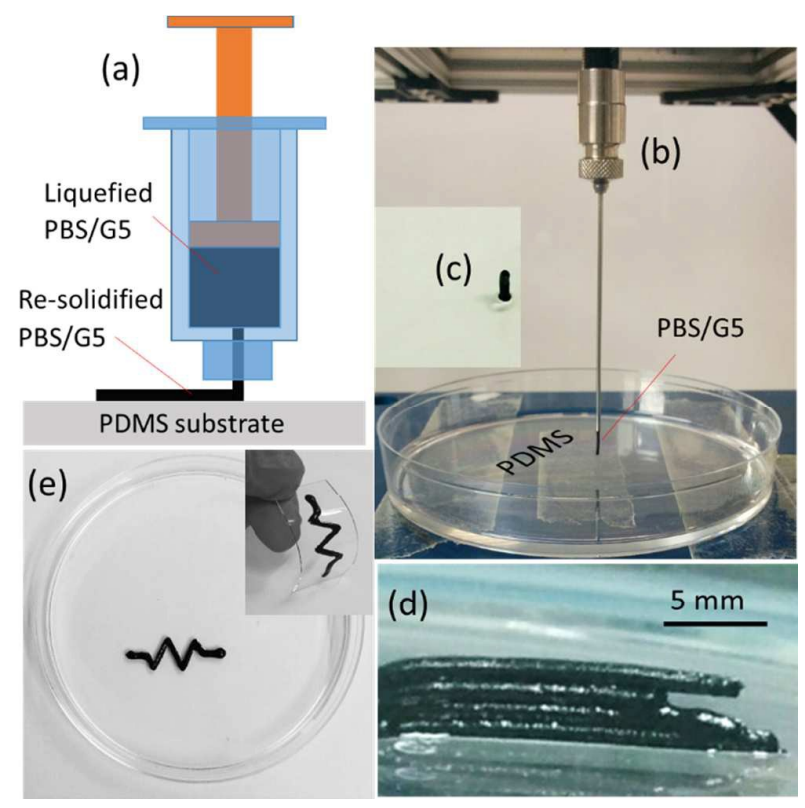


Figure 5. (a) Schematic illustration and (b) photograph of the set-up for 3D printing of PBS/G5 on PDMS substrate. Photographs of printed PBS/G5samples on PDMS substrate: (c) individual filaments, (d) 3D self-supporting filaments, and (e) a zig-zag pattern

\section{D-printed PBS/G5 gas sensor}

The mechanically adaptive property of PBS/G5 can be utilized for 3D extrusion printing: the pre-liquefied material was extruded through the nozzle and the material surface rapidly became solidified in the open air to form self-supporting filaments, as illustrated in Figure 5(a) and 5(b). As a derivative of PDMS, PBS is particularly suitable for printing on flexible PDMS substrates. Figure 5(c) demonstrates an extrusionprinted short filament of PBS/G5 standing upright on PDMS substrate, suggesting their excellent affinity and adhesion. So, PBS/G5 can be used to print 3D self-supporting structures on the substrate. Figure $5(\mathrm{~d})$ demonstrates that PBS/G5 can be added layer by layer to form a well-adhered 3D self-supporting structure due to the rapid solidification. Figure 5(e) presents a 3D-printed gas sensor with a zig-zag pattern on the substrate.

The resistance of PBS/G5 was found chemical-responsive, which was investigated with various chemical saturated vapors: methanol, water, dimethyl carbonate, diethyl ether, 1,4-dioxane, toluene and hexane. For instance, in Figure 6(a), as the PBS/G5 sensor was exposed to methanol vapor, the resistance of the PBS/G5 sensor promptly jumped, and reached to a relatively stable equilibrium value within $50 \mathrm{~min}$. Once removed from methanol vapor, the resistance gradually returned to the initial value within $90 \mathrm{~min}$. It can be seen from Figure 6(b), except in water vapor, that the resistance demonstrated significant and reversible changes for the five organic chemical vapors studied in this work due to the absorption and desorption. To determine the three critical parameters of sensing performance, namely, the sensitivity, response time and recovery time, an exponential decay equation in Equation (5) was applied to fit the experimental data.

$$
y=y_{0}+A_{1} e^{-t / t_{1}}+A_{2} e^{-t / t_{2}}
$$

where $y_{0}, A_{1}, t_{1}, A_{2}$ and $t_{2}$ are fitting parameters ${ }^{57}$. The equation fit the dynamic resistance data well for all the six organic chemical vapors with R-squared coefficients $\left(R^{2}\right)$ in the range of $0.985 \sim 0.999$. The fitting results were listed in Figure $\mathrm{S} 1$ in ESI. The equilibrium value $y_{0}$ for the responding region was taken as the sensitivity. The response and recovery times are defined as the time required to reach $90 \%$ of the maximum resistance change $(\Delta)$ in the corresponding region ${ }^{58}$. The sensing performance of the PBS/G5 sensor in the six chemical vapors, in terms of sensitivity and response and recovery times, is compared in Figure 6(c). The PBS/G5 sensor shows the best two sensitivity data in the two hydrocarbon vapors, hexane and toluene, which are about 5.30 and 5.12 times of magnitude change in the resistance in comparison to the initial value $R_{0}$. This might be attributed to the hydrophobic nature of hexane and toluene which leads to a more effective diffusion into the conductive graphene network and a loosened network, in comparison with the cases with the other four vapors, consequently causing the more significant rises in contact resistance.

Among all the chemical vapors, the PBS/G5 sensor shows the fastest response and recovery times when sensing diethyl ether vapor that are 0.92 and $1.15 \mathrm{~min}$, respectively. The PBS/G5 sensor also exhibits fast response and recovery times for sensing the two hydrocarbon vapors, hexane and toluene vapors, which are 2.1 and $1.3 \mathrm{~min}$ for hexane vapor and 3.9 and $2.5 \mathrm{~min}$ for toluene vapor, respectively. It is noted that the duration for the resistance to reach the equilibrium value is governed by the diffusion rate which is sample-size dependent. Scaling down the sensor size will benefit the response and recovery times.
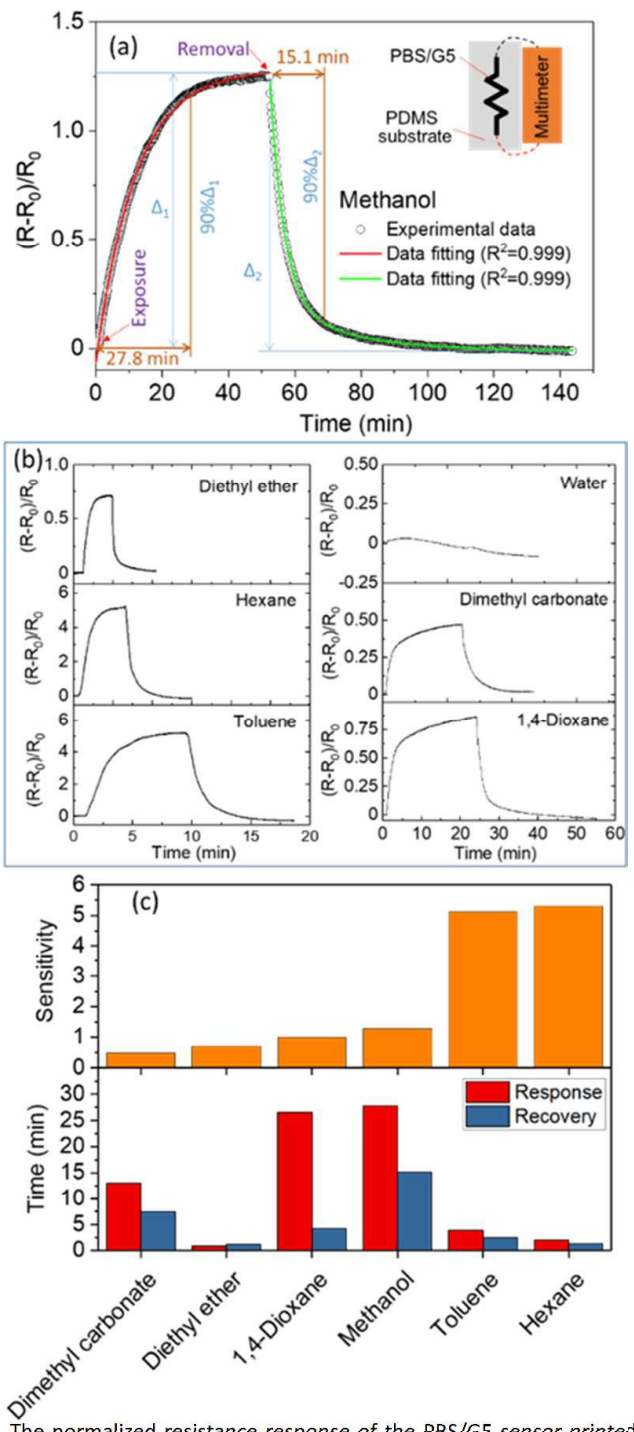

Figure 6. The normalized resistance response of the PBS, $G 5$ sensor printed on PDMS substrate during the exposure to and removal from an atmosphere of chemical saturated vapor: (a) methanol and (b) various chemicals. Inset of (a) is schematic illustration of the experimental set-up for measuring resistance of the PBS/G5 sensor printed on PDMS substrate. (c) The summarized performance of the PBS/G5 sensor for sensing various chemical vapors. 


\section{Conclusions}

Novel self-healing conductive polymer composite ink was formulated for $3 \mathrm{D}$ extrusion printing on popular PDMS flexible substrates. The chemical-activated mechanically adaptive property of PBS enabled the extrusion of polymer composite ink at liquefied state which rapidly restored the solid-like state after exposed to the open air. This is because PBS exhibited a shear-thinning behavior at both liquefied state and solid-like state under a shear amplitude of $1 \%$ according to the rheological measurements in dynamic oscillation mode. The complex viscosity of PBS showed about four orders of magnitude difference at the two ends of frequency $\left(10^{7} \mathrm{~Pa} \mathrm{~s}-\right.$ $\left.10^{3} \mathrm{~Pa} \mathrm{~s}\right)$ in the Carreau-Yasuda model analysis. Chemicalactivated mechanically adaptive property of PBS was studied with methanol vapor as the representative stimulus using FTIR analysis. The underpinning mechanism involved the methanolinduced alcoholysis of the cross-linking boron/oxygen dative bonds in PBS, which led to the reduced viscosity and strength. PBS/graphene composite ink containing 5 vol.\% electrochemically exfoliated graphene (denoted as PBS/G5) was prepared by solution blending. In addition to the shearthinning behavior and mechanically adaptive and mechanically self-healing properties inherited from the matrix PBS, PBS/G5 possessed electrically self-healing capability. These interesting characteristics enabled PBS/G5 to be used as a novel selfhealing conductive ink for 3D extrusion printing on PDMS substrates, and a potential application of this printed object was demonstrated as a sensor to detect various chemical vapors with high sensitivity and moderate response time.

\section{Experimental}

\section{Materials}

Graphite rods (Sigma-Aldrich), ammonium sulfate $\left(\left(\mathrm{NH}_{4}\right)_{2} \mathrm{SO}_{4}\right.$, Acros Organics), boric acid (Sigma-Aldrich), and silicone oil (kinematic viscosity of $350 \mathrm{cSt}$ and density of $0.968 \mathrm{~g} \mathrm{~cm}^{-3}$, VWR) were used as received. The viscosity of silicone oil was approximately $0.34 \mathrm{~Pa} \mathrm{~s}$, calculated from $0.968 \mathrm{~g} \mathrm{~cm}^{-3} \times 350 \mathrm{cSt}$, according to the definition of kinematic viscosity.

\section{Preparation of graphene by electrochemical exfoliation}

Graphene were prepared from graphite by electrochemical exfoliation $^{39}$. Graphite rods were used as the two electrodes, while the anode was the carbon source. The distance between the electrodes was $\sim 2 \mathrm{~cm}$ and the electrolyte was 0.2 $\mathrm{M}\left(\mathrm{NH}_{4}\right)_{2} \mathrm{SO}_{4}$ aqueous solution. Electrochemical exfoliation was carried out by applying a bias voltage of $10 \mathrm{~V}$. The product was collected and washed several times with deionized water by vacuum filtration. The resultant graphene was then dispersed in N-methyl-2-pyrrolidone (NMP) by sonication in an ultrasonic bath (Fisher brand 15051) for $30 \mathrm{~min}$. The dispersion was maintained for $18 \mathrm{~h}$ to precipitate un-exfoliated graphite. Graphene in the top part of the dispersion was precipitated by dilution with 5 -time methanol in volume, and collected by centrifugation. Then the graphene was redispersed at $\sim 10 \mathrm{mg}$
$\mathrm{mL}^{-1}$ in chloroform by probe-type ultrasonication Hielscher UP200S (400 W, $24 \mathrm{kHz}$ ) at 70\% amplitude and 50\% pulse for $1.5 \mathrm{~h}$ and stored before use.

\section{Preparation of polyborosiloxane (PBS)}

PBS was prepared from boric acid and polydimethylsiloxane (silicone oil) following the method previously reported ${ }^{35} .30 \mathrm{~g}$ of boric acid was mixed with $100 \mathrm{~mL}$ silicone oil in a glass vial under mechanical stirring at ambient conditions. During stirring, the temperature was slowly raised to $190{ }^{\circ} \mathrm{C}$. PBS was obtained after allowing the reaction at $190{ }^{\circ} \mathrm{C}$ for $1 \mathrm{~h}$ and cooling down to room temperature. Then, PBS was washed with methanol to remove unreacted boric acid. In this step, PBS was mixed with $100 \mathrm{~mL}$ methanol under stirring, collected using a separatory funnel, and dried in a fume hood for future use.

\section{Preparation of self-healing conductive composite ink (PBS/G5)}

A PBS/graphene composite with 5 vol.\% graphene was obtained by solution blending followed by casting and designated as PBS/G5. Specifically, PBS was weighed and dissolved directly into a measured volume of the graphene/chloroform dispersion. This mixture was stirred for 2 $\mathrm{h}$ and then sonicated in an ultrasonic bath for another hour. The resultant suspension was poured into a polytetrafluoroethylene (PTFE) dish and was kept in a fume cupboard for $24 \mathrm{~h}$ to remove most of the solvent in a fume cupboard until it became non-tacky, and subsequently in vacuum at $40{ }^{\circ} \mathrm{C}$ for $12 \mathrm{~h}$ to remove the residual solvent. The densities of $2.20 \mathrm{~g} \mathrm{~cm}^{-3}$ for graphene and $1.17 \mathrm{~g} \mathrm{~cm}^{-3}$ for $\mathrm{PBS}^{35}$ used for the calculation of the nominal volume percentage of graphene in the composite.

\section{Extrusion printing of PBS/G5}

All printed structures were fabricated using a home-built 3D printer at room temperature throughout the study. The methanol-liquefied PBS/G5 ink was extruded through a metal hub needle with an inner diameter of $410 \mu \mathrm{m}$ (Hamilton) at a constant speed by applying the appropriate pressure. The PDMS elastomer substrates were prepared from Sylgard 184 Kit (Dow Corning) by curing at $40^{\circ} \mathrm{C}$ for $4 \mathrm{~h}$.

\section{Materials Characterization}

Attenuated total Reflectance-Fourier transform infrared (ATRFTIR) spectroscopy was carried out on a Frontier Optica spectrophotometer (PerkinElmer) in the wavenumber region between 4000 to $600 \mathrm{~cm}^{-1}$ with a resolution of $1 \mathrm{~cm}^{-1}$. Tensile tests were carried out using an Instron Model 5543 mechanical tester with a $10 \mathrm{~N}$ load cell and a testing speed of $100 \mathrm{~mm}$ $\mathrm{min}^{-1}$. The specimen dimension was $20 \mathrm{~mm} \times 5 \mathrm{~mm} \times 1 \mathrm{~mm}$. Five specimens were tested for each material. The microstructure of PBS/G5was investigated by scanning electron microscopy (SEM) (Inspect F, FEI), imaged using a $10 \mathrm{keV}$ acceleration voltage. The sample was fractured in liquid nitrogen prior to SEM observation. The topography of graphene on mica 
substrate was analyzed using a Veeco AFM in tapping mode with a scanning rate of $0.5 \mathrm{~Hz}$. Image processing was performed with the XEI software. The electrical properties of the samples were monitored via a benchtop multimeter (Agilent 34401A, Keysight Technologies Inc.). For the conductivity test, a cylinder sample was used and connected to the circuit via two aluminum electrodes. The surface resistance of graphene sheet was measured with a four-point probe on a rectangular sample using the method reported previously ${ }^{59}$. Raman spectroscopy was performed using an in Via Raman microscope. The wavelength of the excitation laser was 514.5 $\mathrm{nm}$ and the power of the laser was kept below $1 \mathrm{mWwithout}$ noticeable sample heating. The laser spot size was $\sim 1 \mu \mathrm{m}$ with a $\times 50$ objective lens (numerical aperture $=0.55$ ). The spectral resolution was $2.5 \mathrm{~cm}^{-1}$ and each spectrum was an average of five acquisitions. Rheological measurements of PBS and PBS/G5were carried out on an MCR 502 rheometer (Anton Paar $\mathrm{GmbH}$ ) with a parallel-plate fixture ( $25 \mathrm{~mm}$ diameter) in a dynamic frequency sweep mode. The rheological properties were recorded as a function of angular frequency ranging from 0.01 to $100 \mathrm{rad} \mathrm{s}^{-1}$ at room temperature. The sample thickness was $\sim 1 \mathrm{~mm}$, and the shear amplitude was kept as a constant of $1 \%$. To measure absorption degree of PBS in methanol saturated vapor, equation (6) was used.

$$
\text { Absorption degree }=\left(W_{2}-W_{1}\right) / W_{1} \times 100 \%
$$

where $W_{1}$ is the original weight of samples and $W_{2}$ is the weight of samples after kept in methanol saturated vapor for $24 \mathrm{~h}$.

\section{Conflicts of interest}

There are no conflicts to declare.

\section{Acknowledgements}

This project has received funding from the European Union's Horizon 2020 research and innovation programme under the Marie Skłodowska-Curie grant agreement No 656467.

\section{Notes and references}

1. G. N. Levy, R. Schindel and J. P. Kruth, CIRP Annals, 2003, 52, 589-609.

2. X. Wang, M. Jiang, Z. Zhou, J. Gou and D. Hui, Compos. PART BENG, 2017, 110, 442-458.

3. B. Y. Ahn, E. B. Duoss, M. J. Motala, X. Guo, S.-I. Park, Y. Xiong, J. Yoon, R. G. Nuzzo, J. A. Rogers and J. A. Lewis, Science, 2009, 323, 1590-1593.

4. I. Zein, D. W. Hutmacher, K. C. Tan and S. H. Teoh, Biomaterials, 2002, 23, 1169-1185.

5. J. M. Williams, A. Adewunmi, R. M. Schek, C. L. Flanagan, P. H. Krebsbach, S. E. Feinberg, S. J. Hollister and S. Das, Biomaterials, 2005, 26, 4817-4827.

6. C. N. Ionita, M. Mokin, N. Varble, D. R. Bednarek, J. Xiang, K. V. Snyder, A. H. Siddiqui, E. I. Levy, H. Meng and S. Rudin, Proc. SPIE, 2014, 9038, 90380M.
7. M. N. Cooke, J. P. Fisher, D. Dean, C. Rimnac and A. G. Mikos, J. Biomed. Mater. Res. Part B Appl. Biomater, 2003, 64B, 65-69.

8. D. K. Patel, A. H. Sakhaei, M. Layani, B. Zhang, Q. Ge and S. Magdassi, Adv. Mater., 2017, 29, 1606000.

9. J. R. Tumbleston, D. Shirvanyants, N. Ermoshkin, R. Janusziewicz, A. R. Johnson, D. Kelly, K. Chen, R. Pinschmidt, J. P. Rolland, A. Ermoshkin, E. T. Samulski and J. M. DeSimone, Science, 2015, 347, 1349-1352.

10. T. J. Hinton, Q. Jallerat, R. N. Palchesko, J. H. Park, M. S. Grodzicki, H.-J. Shue, M. H. Ramadan, A. R. Hudson and A. W. Feinberg, Sci. Adv., 2015, 1, e1500758.

11. L. Ouyang, C. B. Highley, C. B. Rodell, W. Sun and J. A. Burdick, ACS Biomater. Sci. \& Eng., 2016, 2, 1743-1751.

12. Y. Yagci, S. Jockusch and N. J. Turro, Macromolecules, 2010, 43, 6245-6260.

13. Y. Xu, X. Wu, X. Guo, B. Kong, M. Zhang, X. Qian, S. Mi and W. Sun, Sensors, 2017, 17, 1166.

14. S. J. Leigh, R. J. Bradley, C. P. Purssell, D. R. Billson and D. A. Hutchins, PLOS ONE, 2012, 7, e49365.

15. J. Liu, T.-M. Fu, Z. Cheng, G. Hong, T. Zhou, L. Jin, M. Duvvuri, Z. Jiang, P. Kruskal, C. Xie, Z. Suo, Y. Fang and C. M. Lieber, Nat Nano, 2015, 10, 629-636.

16. S.-Y. Wu, C. Yang, W. Hsu and L. Lin, Microsys. \& Nanoeng., 2015, 1, 15013.

17. S. Sundaram, D. S. Kim, M. A. Baldo, R. C. Hayward and W. Matusik, ACS Appl. Mater. Interfaces, 2017, 9, 32290-32298.

18. F. Garnier, R. Hajlaoui, A. Yassar and P. Srivastava, Science, 1994, 265, 1684-1686.

19. Z. Bao, Y. Feng, A. Dodabalapur, V. R. Raju and A. J. Lovinger, Chem. Mater., 1997, 9, 1299-1301.

20. B. A. Ridley, B. Nivi and J. M. Jacobson, Science, 1999, 286, 746749.

21. H. Sirringhaus, T. Kawase, R. H. Friend, T. Shimoda, M. Inbasekaran, W. Wu and E. P. Woo, Science, 2000, 290, 21232126.

22. D. B. Chrisey, Science, 2000, 289, 879-881.

23. Y. Zhang, F. Zhang, Z. Yan, Q. Ma, X. Li, Y. Huang and J. A. Rogers, Nat. Rev. Mater., 2017, 2, 17019.

24. M. S. Mannoor, Z. Jiang, T. James, Y. L. Kong, K. A. Malatesta, W. O. Soboyejo, N. Verma, D. H. Gracias and M. C. McAlpine, Nano Lett., 2013, 13, 2634-2639.

25. B. Y. Ahn, D. J. Lorang and J. A. Lewis, Nanoscale, 2011, 3, $2700-$ 2702.

26. M. Areir, Y. Xu, D. Harrison and J. Fyson, J. Mater. Sci.: Mater. Electron. , 2017, 28, 18254-18261.

27. J. T. Muth, D. M. Vogt, R. L. Truby, Y. Mengüç, D. B. Kolesky, R. J. Wood and J. A. Lewis, Adv. Mater., 2014, 26, 6307-6312.

28. J. S. Park, T. Kim and W. S. Kim, Sci. Rep., 2017, 7, 3246.

29. J. Y. Kim, S. Ji, S. Jung, B.-H. Ryu, H.-S. Kim, S. S. Lee, Y. Choi and S. Jeong, Nanoscale, 2017, 9, 11035-11046.

30. D. Zhang, B. Chi, B. Li, Z. Gao, Y. Du, J. Guo and J. Wei, Synth. Met., 2016, 217, 79-86.

31. J. F. Christ, N. Aliheidari, A. Ameli and P. Pötschke, Mater. Des., 2017, 131, 394-401.

32. A. E. Jakus, E. B. Secor, A. L. Rutz, S. W. Jordan, M. C. Hersam and R. N. Shah, ACS Nano, 2015, 9, 4636-4648.

33. E. D'Elia, S. Barg, N. Ni, V. G. Rocha and E. Saiz, Adv. Mater., 2015, 27, 4788-4794.

34. R. Cross, Am. J. Phys., 2012, 80, 870-875.

35. C. S. Boland, U. Khan, G. Ryan, S. Barwich, R. Charifou, A. Harvey, C. Backes, Z. Li, M. S. Ferreira, M. E. Möbius, R. J. Young and J. N. Coleman, Science, 2016, 354, 1257-1260. 
36. M. P. Goertz, X. Y. Zhu and J. E. Houston, J. Polym. Sci., Part B: Polym. Phys., 2009, 47, 1285-1290.

37. X. Li, D. Zhang, K. Xiang and G. Huang, RSC Adv., 2014, 4, 3289432901.

38. T. Wu and B. Chen, ACS Appl. Mater. Interfaces, 2016, 8, 2407124078.

39. K. Parvez, Z.-S. Wu, R. Li, X. Liu, R. Graf, X. Feng and K. Müllen, J. Am. Chem. Soc., 2014, 136, 6083-6091.

40. A. C. Ferrari, J. C. Meyer, V. Scardaci, C. Casiraghi, M. Lazzeri, F. Mauri, S. Piscanec, D. Jiang, K. S. Novoselov, S. Roth and A. K. Geim, Phys. Rev. Lett., 2006, 97, 187401.

41. T. Yang, L.-h. Liu, J.-w. Liu, M.-L. Chen and J.-H. Wang, J. Mater. Chem., 2012, 22, 21909-21916.

42. T. B. Limbu, F. Mendoza, D. Barrionuevo, J. Carpena, B. Maruyama, R. S. Katiyar, B. R. Weiner and G. Morell, AlP Adv., 2016, 6, 035319.

43. F. J. H. Gijsen, E. Allanic, F. N. van de Vosse and J. D. Janssen, J. Biomechanics, 1999, 32, 705-713.

44. P. J. Carreau, Trans. Soc. Rheol., 1972, 16, 99-127.

45. W. Gleissle and B. Hochstein, J. Rheol., 2003, 47, 897-910.

46. L. Shan, Y. Tan and Y. Richard Kim, Constr. Build. Mater., 2012, 37, 716-722.

47. W. P. Cox and E. H. Merz, J. Polym. Sci., 1958, 28, 619-622.

48. G. Marrucci, J Nonnewton Fluid Mech., 1996, 62, 279-289.

49. L. M. Johnson, L. Gao, C. W. Shields IV, M. Smith, K. Efimenko, K. Cushing, J. Genzer and G. P. López, J. Nanobiotechnology, 2013, 11, 1-8.

50. S. C. Bae, H. Lee, Z. Lin and S. Granick, Langmuir, 2005, 21, 5685-5688.

51. M. Nour, K. Berean, M. J. Griffin, G. I. Matthews, M. Bhaskaran, S. Sriram and K. Kalantar-zadeh, Sensor Actuat. B-Chem., 2012, 161, 982-988.

52. Z. Liu, S. J. Picken and N. A. M. Besseling, Macromolecules, 2014, 47, 4531-4537.

53. J. A. Faniran and H. F. Shurvell, Can. J. Chem., 1968, 46, 20892095.

54. C. C. Perry, X. Li and D. N. Waters, Spectrochim. Acta A, 1991, 47, 1487-1494.

55. T. Lagström, T. A. Gmür, L. Quaroni, A. Goel and M. A. Brown, Langmuir, 2015, 31, 3621-3626.

56. S. L. Warring, D. A. Beattie and A. J. McQuillan, Langmuir, 2016, 32, 1568-1576.

57. S. Ranwa, M. Kumar, J. Singh, M. Fanetti and M. Kumar, J. Appl. Phys., 2015, 118, 034509.

58. M. Liu, S. P. Ren, R. Y. Zhang, Z. Y. Xue, C. R. Ma, M. L. Yin, X. Xu, S. Y. Bao and C. L. Chen, Sci. Rep., 2015, 5, 10784.

59. F. M. Smits, Bell Syst. Tech. J., 1958, 37, 711-718. 
A graphene/polyborosiloxane composite exhibited self-healing, adaptive and electrically conductive properties which could be $3 \mathrm{D}$ printed into gas sensors.
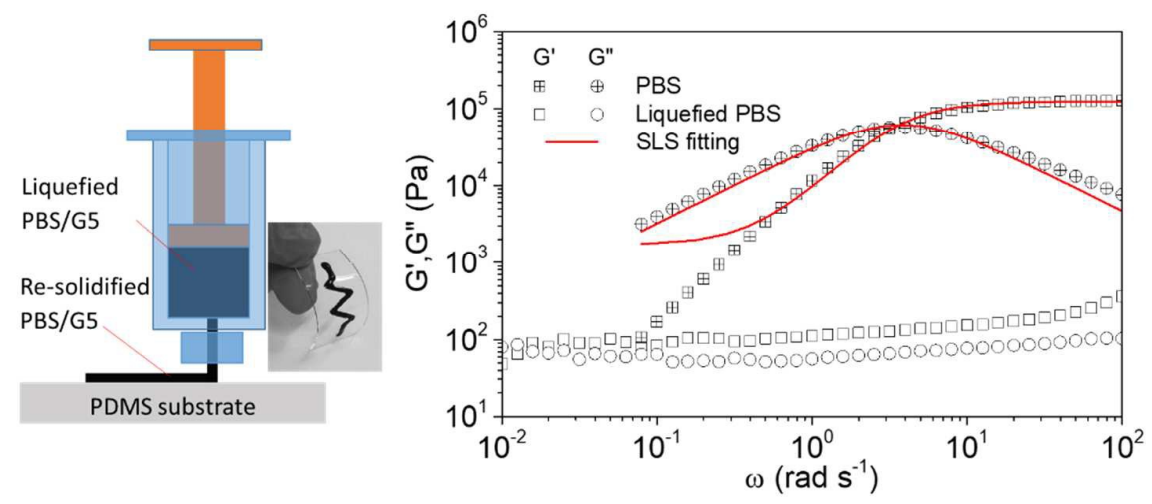